\title{
Consumer preference for entertainment parks in India
}

\section{Jayanthi Ranjan and Gunjan Malhotra*}

\author{
Institute of Management Technology - IMT, \\ Ghaziabad, Uttar Pradesh, India \\ E-mail: jranjan@imt.edu \\ E-mail: gmalhotra@imt.edu \\ E-mail: mailforgunjan@gmail.com \\ *Corresponding author
}

\begin{abstract}
This paper investigates the research question through empirical study on ever-increasing number of parks and many entertainment parks expanding their activities in India. This paper assesses empirically on how do the parks survive. This is pressed in the Indian context, where the entertainment park business is facing changes in the form of a more educated and increasingly youthful population who do not mind spending but demand quality, and visitors who are more thoughtful and discriminating about how the available resources of free time and disposable income are used. This paper attempts to analyse different entertainment parks situated in India and conducts a live empirical research on consumer's choice behaviour in selecting the park. The authors hope that such information would be useful for researchers, consumers, practitioners and businessmen to open/expand/increase their portfolios further.
\end{abstract}

Keywords: consumer preference; entertainment parks; India; factor analysis; tourism.

Reference to this paper should be made as follows: Ranjan, J. and Malhotra, G. (2011) 'Consumer preference for entertainment parks in India', Int. J. Built Environment and Asset Management, Vol. 1, No. 1, pp.94-102.

Biographical notes: Jayanthi Ranjan is a Professor in the field of Data Mining. She has done MCA. She has a total of 129 publications and published 10 edited books. She received best papers awards twice. She is also the recipient of 'Best Teacher Award' from AIMA-Ghaziabad Management Association, India, for her contribution to teaching and research. She was awarded AIMS Association of International Management Scholars, Best Woman Management Researcher 2009. She is serving on the editorial board in Information Technology Journal, IJCVR, IJECRM, JATIT and IJIKM. She is also the Editor of IJCCT. She is also the Chairman of International Relations, IMT Ghaziabad.

Gunjan Malhotra is an Assistant Professor in Institute of Management Technology (IMT), Ghaziabad, India. She holds a Doctoral Degree, MPhil and MA in Economics from DAVV, Indore, MP and BA in Economics from Gargi College, Delhi University, New Delhi, India. She has a teaching experience of over eight years in the fields of Operations and Econometrics. Her research interest includes international, environmental, financial volatility, industrial and business economics using relevant econometrics, statistical and quantitative techniques. She has actively contributed research papers in various international and national journals and conferences.

Copyright (C) 2011 Inderscience Enterprises Ltd. 


\section{Introduction}

Destinations are amalgams of tourism products and services, which offer an integrated experience to tourists (Buhalis, 2000). The evolution of mass tourism in the Indian economy has paced up since liberalisation policies adopted by its government, a number of rating and evaluation systems were developed for a variety of tourism and hospitality products then. These systems were based on a variety of attributes that were associated with specific products such as hotels, airlines or restaurants. These rating and evaluation systems were designed in makings consumers informed about various travel and tourism products. This makes available the variety of travel packages that can be selected by the upcoming tourists (Ingram, 1996).

For several decades, the World Tourism Organization sought to develop in the new millennium tourism that will be the single largest industry in the world. These rating systems have been practiced along various attractive destinations across the world (Ingram, 1996). Thus, the lodging industry classification plays an important role in any country to increase and motivate tourism. Entertainment parks are star players in the tourism industry and play a special and important role in generating tourism demand. Entertainment (or amusement) parks are one of the main motivators for tourism trips to many destinations and core elements of the tourism product. For example, Zoltak (1998a) has been argued that many of the Asian countries such as China, Thailand and Malaysia are now actively promoting the construction of major entertainment parks in their countries to increase tourism revenues. Previously, many regions and countries around the world especially in developed countries have supported the growth of entertainment parks as an attractive option to increase direct economic input. The type of entertainment parks nowadays available to the public covers a wide variety of businesses ranging from the well-known large-scale entertainment or leisure parks with 'thrill adventure' rides, to historic properties, museums and art galleries, religious sites, industrial plants, zoos and wildlife park.

The question is, given an ever-increasing number of parks and many parks expanding their activities, how do the parks survive? This question is especially pressing in the Indian context, where the entertainment park business is facing changes in the form of a more educated and increasingly youthful population who do not mind spending but demand quality, and visitors who are more thoughtful and discriminating about how the available resources of free time and disposable income are used. Therefore, this paper attempts to analyse different entertainment parks situated in India and conducts a live empirical research on consumer's choice behaviour in selecting the park. The authors hope that such information would be useful for researchers, consumers, practitioners and businessmen to open/expand/increase their portfolios further.

\section{Literature review}

The entertainment park industry is of high economic significance. The world's top 25 parks hosted 187.6 million guests in 2007, up by $0.5 \%$ from 2006 (Rubin, 2008). Worldwide revenues in 2003 were $\$ 19.78$ billion, which were estimated to increase to $\$ 24.71$ billion by 2008 (Pricewaterhouse Coopers, 2008). The entertainment parks, which were developed at the turn of this century, consisted of a mixture of entertainment, rides, 
games and tests of skill provided at fairs, carnivals, circuses and frequently they had an outdoor garden for drinking (Pearce, 1988).

Another group of studies looked at the impact of consumers' experience with the product on its perceived value. Mooy and Robben's $(1998,2002)$ research supported the view that the communicative abilities of products can effectively be used to enhance consumers' positive evaluation of the product. Their studies also confirmed the hypothesis that consumers' direct experience with the product enhanced consumers' ability to process product-related information, but not necessarily their motivation to process the information. Consumer experience with products was also investigated by Mason and Bequette (1998), who suggested that consumer product evaluations were often influenced by information contained in their memories.

The number of studies that has been conducted in this field is rather limited in India, although in the recent year, entertainment parks have become a more significant topic of analysis. Pearce and Rutledge (1994) set out criteria for the success of entertainment parks and are largely based on the opinions of operators, consultants and marketers (Gratton, 1992; Lavery and Stevens, 1990; Martin and Mason, 1993; Tourism Research and Marketing, 1996). Although this set of studies does not specifically focus on entertainment park customer choice behaviour, it does provide insight into more general issues in the area of entertainment park planning and management.

Martin and Mason (1993) consider the long-term future for tourist attractions. They examine factors such as renewed economic growth, new consumer lifestyles and priorities, demographic changes and new technologies. It is concluded that attractions have to cater for visitors who are more demanding and discriminating, as well as more active and more purposeful in their choice of destination. There will be a shift in emphasis from passive fun to active learning, and the quality and genuineness of visitor experience will be crucial to future success in the competitive market. They also direct attention to the necessity of meeting changing tourist demand to make entertainment parks successful in the coming decade.

McClung (1991) also studied which factors are influential in the selection of an entertainment park. He examined data from over 3,000 households in 10 eastern metropolitan areas in the USA. Respondents indicated four important influencing factors in their consideration of whether or not to attend an entertainment park: climate, preference for entertainment parks, children's desire to attend and cost.

We observed that very few researches have been conducted on the visitor's choice pattern and behaviour in the context of entertainment parks in India. Indian tourism has almost doubled in the last decade, but little work has been done to develop models that systematically relate the characteristics of entertainment park products and services to the choices that tourists make. In this study, an attempt has been made to analyse different entertainment parks in India and the visitors' choice behaviour in selecting a particular park within regional context. This will help to assist the development of strategic and tactical plans to provide a number of policy implications for suppliers of entertainment parks. 


\section{Research methods}

\subsection{Research strategy}

A positivist approach involving structured questionnaire was used due to the wide number of responses required within a limited time period. This involved a wide number of respondents situated all over India. The questionnaires were specific and structured to obtain the data about the entertainment parks selected keeping in mind the objectives of the study namely Ramoji film city, Vegaland, Entertainment city, Essel world and Fun n Food village. There are similarities among these entertainment fun and food parks based on their entrance fees charged, rides both for children and for adults, and eating joint serving varieties of foods as per the taste of the individuals. An entertainment park is one of the finest places to be visited by both domestic and foreign tourists, where they can simply have fun and spend quality time with their family and friends.

In this survey, 341 questionnaires were sent out to different respondents across India which includes states such as Rajasthan, Uttar Pradesh, Karnataka, Andhra Pradesh, Punjab, etc. with demographic details of gender, age, marital status and the Indian state from where they belong to; and 270 questionnaires were returned (79.1\%). Questionnaire format guidelines outlined by Gill and Johnson (1991) were followed. The format of the questionnaire was chosen based on the research objectives and the findings from the literature search. Question categories provided by Baxter et al. (1996) were used. Particular attention was paid to the wording and phraseology of questions, to ensure a fair and appropriate response.

Secondly, the fieldwork involved piloting the questionnaire on colleagues and students to gain their views on its usability and the amount of time required in completing it. Several minor corrections were made. To ensure a better response, a number of steps were taken initially in designing the questionnaire: attaching a covering letter, keeping the questions simple and short, attaching a prepaid envelope and phoning to confirm the respondent was genuine. Finally, the confidentiality of the respondents was assured by eliminating the names and addresses of the respondents unless they chose to provide them.

Thirdly, the data was aggregated and analysed using Microsoft Excel and SPSS version 17. Attempts were made to keep illustrations simple to assist the researchers to make relevant sense of the responses. The respondents were given about two weeks to return the questionnaire. The findings were written up and analysed. The results were then linked back to the literature, where appropriate, to test current literature.

The use of questionnaire had several advantages and disadvantages (Bell and Newby, 1977; Oppenheim, 1966). To overcome the disadvantages associated with questionnaires, semi-structured interviews and focus groups can be used and may be used.

\subsection{Data collection}

Questionnaire was used to ask a specific number of questions on the average time spent by them in entertainment parks, their awareness of different parks and how many times they have visited such parks, the purpose for which they visit such parks, their preferred season and rides to visit such parks and other topics that are linked to the research aim and sub-research questions (RQs). 


\section{Findings}

The questionnaire explored whether the respondents visited entertainment parks at least once were considered or if they intended to visit in the future. In undertaking this research, we generated a number of RQs that were based on the aims of this research. These RQs are:

1 to explore the role of entertainment parks in India in fulfilling the customers preferences

2 to what extent is entertainment parks are providing satisfaction/entertainments to consumers and assisting Indian consumers with their choices and preferences.

\subsection{Analysis of data}

The responses to our questionnaire survey revealed that a majority of the respondents (94\%) visited entertainment parks or intended to visit one, and just $6 \%$ respondents said $\mathrm{s} /$ he did not visit entertainment parks but intended to visit one. This indicated that, at least as far as this survey is concerned, entertainment parks in India are widely known in India and are important in day-to-day working Indian consumers and the successful functioning of such parks in India. The questionnaires were administered across Indian states to a variety of organisations.

This concurs with entertainment park and tourism writers (Martin and Mason, 1993; Zoltak, 1998b) who write that there is a long-term future of tourist attractions and parks across globe. The success for entertainment parks is largely based on the opinions of operators, consultants and marketers (Gratton, 1992; Lavery and Stevens, 1990).

When asked about the level at which they were visiting entertainment parks in a month or year, the respondents stated that such visits are being perceived and utilised to know more about the different Indian cultures and cuisines, from very operational level they visited these parks to have more leisure time and quality time spending with their family and friends. Almost all respondents who indicated that they were visiting some sort of fun parks and said that they were visiting entertainment parks for the first time (69\% respondents), whereas $47 \%$ respondents said that they visited frequently and they have clear knowledge.

We have used factor analysis test to find the major factors that impacts the decision of the respondents when they choose a particular entertainment park in India. The results are shown in Tables 1-3. The Kaiser-Meyer-Olkin (KMO) measure of sampling adequacy was as high as 0.708 and the Bartlett's test of sphericity rejected the null hypothesis that the correlation matrix was an identity matrix.

Table 1 KMO and Bartlett's test for factor analysis

\begin{tabular}{ll}
\hline KMO measure of sampling adequacy & 0.708 \\
Bartlett's test of sphericity approximately chi-square & 467.633 \\
d.f. & 36 \\
Significance & 0.000 \\
\hline
\end{tabular}


Table 2 Total variance explained through principal component method

\begin{tabular}{|c|c|c|c|c|c|c|c|c|c|}
\hline \multirow[b]{2}{*}{ Component } & \multicolumn{3}{|c|}{ Initial eigenvalues } & \multicolumn{3}{|c|}{$\begin{array}{c}\text { Extraction sums of squared } \\
\text { loadings }\end{array}$} & \multicolumn{3}{|c|}{ Rotation sums of squared loadings } \\
\hline & Total & $\begin{array}{c}\% \text { of } \\
\text { variance }\end{array}$ & $\begin{array}{c}\text { Cumulative } \\
\%\end{array}$ & Total & $\begin{array}{c}\% \text { of } \\
\text { variance }\end{array}$ & $\begin{array}{c}\text { Cumulative } \\
\%\end{array}$ & Total & $\begin{array}{c}\% \text { of } \\
\text { variance }\end{array}$ & $\begin{array}{c}\text { Cumulative } \\
\%\end{array}$ \\
\hline 1 & 3.039 & 33.764 & 33.764 & 3.039 & 33.764 & 33.764 & 2.611 & 29.016 & 29.016 \\
\hline 2 & 1.267 & 14.081 & 47.845 & 1.267 & 14.081 & 47.845 & 1.472 & 16.361 & 45.377 \\
\hline 3 & 1.060 & 11.780 & 59.625 & 1.060 & 11.780 & 59.625 & 1.282 & 14.248 & 59.625 \\
\hline 4 & 0.897 & 9.972 & 69.597 & & & & & & \\
\hline 5 & 0.778 & 8.639 & 78.236 & & & & & & \\
\hline 6 & 0.680 & 7.556 & 85.792 & & & & & & \\
\hline 7 & 0.550 & 6.114 & 91.906 & & & & & & \\
\hline 8 & 0.457 & 5.077 & 96.983 & & & & & & \\
\hline 9 & 0.272 & 3.017 & 100.000 & & & & & & \\
\hline
\end{tabular}

Table 3 Rotated component matrix using principal component analysis and varimax with Kaiser normalisation

\begin{tabular}{lrcc}
\hline & \multicolumn{3}{c}{ Component method } \\
\cline { 2 - 4 } & 1 & 2 & 3 \\
\hline Culture & 0.620 & 0.148 & 0.044 \\
Cuisine & -0.195 & 0.145 & 0.810 \\
Music & 0.295 & 0.029 & 0.643 \\
Monuments & 0.310 & 0.756 & 0.088 \\
History & 0.057 & 0.896 & 0.077 \\
Handicraft & 0.755 & 0.167 & 0.125 \\
Festivals & 0.575 & -0.007 & 0.405 \\
Religious & 0.698 & 0.090 & -0.111 \\
Handloom & 0.783 & 0.138 & 0.067 \\
\hline
\end{tabular}

To obtain a clearer picture of groupings of the attributes that the respondent keeps in mind before visiting an entertainment park of his choice, a factor analysis has been conducted. The resulting eigenvalues for three common factors were only greater than unity. We reached the same conclusion using the scree plot (not reported but available from the authors upon request) as a criterion to determine the number of common factors. The proportion (per cent) of variance explained by each factor is also shown in Table 2, indicating that these three factors altogether account for about $59.2 \%$ of the total variance using the principal component method.

We then rotate the resulting factors by the varimax method to facilitate the interpretation of the results presented in Table 3 . As can be seen, the first factor includes culture, handicraft, festivals, religious and handlooms that interest consumer's choice behaviour. Therefore, we can name this factor as cultural values. The second factor includes monuments and history, and thus can be named as historical factor. While the third factor possesses cuisine and music, thus can be named as leisure factor. Overall, we 
found that three factors are the main reasons for consumers' visit in the entertainment parks. They are cultural, historical and leisure.

The respondents were asked, 'how important is entertainment parks'. This question asked respondents to evaluate the entertainment park offerings. The definitions of system usefulness differ for different individuals. The replies overall suggest that respondents do view entertainment park as very important in visiting them. The respondents provided the following reasons: entertainment parks were very important in relaxing $(50 \%$ respondents), entertainment parks provide/help consumers amusement $(25 \%$ respondents), important for providing information related to entertainment parks to consumers. About $13 \%$ respondents did not comment about how entertainment parks will help them. Only $6 \%$ said entertainment parks are not important and did not see it as too important.

Furthermore, respondents were asked, 'how they could make a good use of entertainment park'. This question asked the respondents to refer to their experience and expertise to imagine as to how they can use a day off. The responses given by respondents were that it did or could:

1 help to shift the existing ways of perceiving entertainment parks in India

2 reduce stress and enhance/increase excitements to visit these entertainment parks more often.

About $38 \%$ of the respondents did not reply or comment on this question. Perhaps due to the open-ended answer required or due to lack of imagination or due to the difficulty involved in the response required. We cannot assume this because of low responses. But overall, the responses to this question suggest that consumers are becoming more aware of entertainment parks and get a chance to spend time with family and friends.

The response to our questions revealed that the respondents have individual spending habits, autonomous and independent to choose entertainment parks. The respondents were asked to indicate if they are working or not. It was strategy of the researchers not to include the respondents who were not working. But all respondents who completed questionnaires were working, although in several hierarchical ranks. We aimed to obtain responses from those people who were earning.

\section{Conclusions}

This research focused on the role of entertainment parks in assisting Indian consumers to understand more about the variety of activities such as rides, eating joints, popular seasonal cuisines, services, cultural values and quality of these parks available in India. This paper looked at the impact of entertainment parks on the mind of Indian consumers. The results revealed that there are three factors: cultural, historical and leisure that play an important role in helping respondents to choose an entertainment park they wish to visit on weekends with their family and friends. Most of the working people along with their families were visiting entertainment parks, at least once in a year and some were visiting these parks on a regular basis viz. 3-4 times in a year or even more. The once in life time visitors were very less. The respondents generally believed that entertainment parks were important in allowing them to perform things that they cannot think of doing at their work place more efficiently, effectively and in relaxing and cool manner without 
any professional tensions of their organisations. This confirms that logistics of the entertainment parks and their quality and fun-filled environment are vital in helping Indian consumers to choose the park they want to visit. This had increased the demand of such more entertainment parks in India which are ever-improving on the kinds of service and quality they provide to their consumers. This will help the parks' owners to retain their existing customers and increase more footfalls in the near future.

\section{References}

Baxter, L., Hughes, C. and Tight, M. (1996) How to Research. Buckingham: Open University Press.

Bell, C. and Newby, H. (1977) Doing Sociological Research. London: Allen and Unwin.

Buhalis, D. (2000) 'Marketing the competitive destination of the future', Tourism Management, Vol. 21, No. 1, pp.97-116.

Gill, J. and Johnson, P. (1991) Research Methods for Managers. London: Paul Chapman Publishing Ltd.

Gratton, C. (1992) 'A perspective on European leisure markets', Paper presented at the Joint Conference of LSA and VVS, Tilburg, 10-12 December 1992.

Ingram, H. (1996) 'Classification and grading of smaller hotels, guesthouses and bed and breakfast accommodation', Int. J. Contemporary Hospitality Management, Vol. 8, No. 5, pp.30-34.

Lavery, P. and Stevens, T. (1990) 'Attendance trends and future developments at Europe's leisure attractions', EIU Travel and Tourism Analyst, Vol. 2, pp.52-75.

Martin, W.H. and Mason, S. (1993) 'The future for attractions - meeting the needs of the new consumers', Tourism Management, Vol. 1, pp.34-40.

Mason, K. and Bequette, J. (1998) 'Product experience and consumer product attribute inference accuracy’, Journal of Consumer Marketing, Vol. 15, No. 4, pp.319-357.

McClung, G.W. (1991) 'Theme park selection: factors influencing attendance', Tourism Management, Vol. 3, pp.132-140.

Mooy, S.C. and Robben, H.S.J. (1998) 'How consumers learn from and about products: the impact of direct experience', Advances in Consumer Research, Vol. 25, No. 1, pp.318-323.

Mooy, S.C. and Robben, H.S.J. (2002) 'Managing consumers' product evaluation through direct product experience', Journal of Product \& Brand Management, Vol. 11, No. 7, pp.432-446.

Oppenheim, A.N. (1966) Questionnaire Design and Attitude Measurement. London: Heinemann.

Pearce, P.L. (1988) The Ulysses Factor: Evaluating Visitors in Tourist Settings. New York: Springer-Verlag.

Pearce, P.L. and Rutledge, J. (1994) 'Architectural design and planning of tourist facilities: theme park planning and design', Proceedings of the Environments for Tourism Conference, Las Vegas, pp.320-349.

Pricewaterhouse Coopers (2008) Global Entertainment and Media Outlook: 2004-2008 Report. New York: Pricewaterhouse Coopers.

Rubin, J. (2008) 2007 Themed Entertainment Association/Economics Research Associates Attraction Attendance Report. Available at: http://www.themeit.com/attendance_report2007. pdf.

Tourism Research and Marketing (1996) Theme Parks: UK and International Markets 1993. London: Tourism Research and Marketing.

Zoltak, J. (1998a) 'China: theme park market for the new millennium?', Amusement Business, New York, 14 September 1998.

Zoltak, J. (1998b) 'Seagram enters theme park business in Europe', Amusement Business, New York, 29 June 1998. 


\section{Bibliography}

Ah-Keng, K. (1994) 'Assessing the market receptivity of a new theme park in Singapore: an exploratory study', Journal of Travel Research, Vol. 32, pp.44-50.

Cliff, J. (2007) 'It's all in the numbers', Fun World, Vol. 23, No. 11, pp.121-133.

IAAPA (2008) Amusement Park and Attractions Industry Statistics. International Association of Amusement Parks and Attractions. Available at: http://www.iaapa.org/pressroom/ Amusement_Park_Industry_Statistics.asp.

International Association of Amusement Parks and Attractions (IAAPA) (2009) U.S. Amusement Park Attendance and Revenue History. Available at: http://www.iaapa.org/pressroom/ Amusement_Park_Attendance_Revenue_History.asp.

Kemperman, A.D.A.M. (2000) 'Temporal aspects of theme park choice behavior', PhD Thesis, Technische Universiteit Eindhoven, Eindhoven, The Netherlands.

Kemperman, A.D.A.M., Borgers, A.W.J., Oppewal, H. and Timmermans, H.J.P. (2000) 'Consumer choice of theme parks: a conjoint choice model of seasonality effects and variety seeking behavior', Leisure Science, Vol. 22, No. 1, pp.1-18.

Kemperman, A.D.A.M., Borgers, A.W.J. and Timmermans, H.J.P. (2002) 'A semiparametric hazard model of activity timing and sequencing decisions during visits to theme parks using experimental design data', Tourism Analysis, Vol. 7, No. 1, pp.1-13.

Lawson, R. (1991) 'Patterns of tourist expenditure and types of vacation across the family life cycle', Journal of Travel Research, Vol. 29, pp.12-24.

Middleton, V.T.C. (1988) Marketing in Travel and Tourism. Oxford: Heinemann Professional Publishing Ltd.

Moutinho, L. (1988) 'Amusement park visitor behavior - Scottish attitudes', Tourism Management, Vol. 9, No. 4, pp.291-300.

PricewaterhouseCoopers LLP (2007) Global Entertainment and Media Outlook 2007-2011 Report. New York: PricewaterhouseCoopers LLP.

PricewaterhouseCoopers LLP (2010) Global Entertainment and Media Outlook: 2006-2010 Report. New York: PricewaterhouseCoopers LLP.

The Economist (1999) Business: Fantasyland. London, 6 November, p.67.

World Tourism Organization (2003) Djerba Declaration on Tourism Climate Change. Available at: www.world-tourism.org/sustainable/climate/decdjerba-eng.pdf. 